\title{
Circadian production of melatonin in cartilage modifies rhythmic gene expression
}

\author{
Shanqi Fu', Miho Kuwahara'1, Yoko Uchida², Sei Kondo', Daichi Hayashi'1, Yuji Shimomura', Asami Takagaki", \\ Takashi Nishida1, Yusuke Maruyama³, Mika Ikegame4, Atsuhiko Hattori³, Satoshi Kubota1 and Takako Hattori1 \\ 1'Department of Biochemistry and Molecular Dentistry, Okayama University Graduate School of Medicine, Dentistry and Pharmaceutical Sciences, \\ Okayama, Japan \\ 2Department of Preventive Dentistry, Okayama University Graduate School of Medicine, Dentistry and Pharmaceutical Sciences, Okayama, Japan \\ 3Department of Biology, College of Liberal Arts and Sciences, Tokyo Medical and Dental University, Ichikawa, Chiba, Japan \\ ${ }^{4}$ Department of Oral Morphology, Okayama University Graduate School of Medicine, Dentistry and Pharmaceutical Sciences, Okayama, Japan \\ Correspondence should be addressed to T Hattori: hattorit@md.okayama-u.ac.jp
}

\begin{abstract}
Endochondral ossification, including bone growth and other metabolic events, is regulated by circadian rhythms. Herein, we provide evidence that melatonin has a direct effect on the circadian rhythm of chondrocytes. We detected mRNA expression of the genes which encode the melatonin-synthesizing enzymes AANAT (arylalkylamine $\mathrm{N}$-acetyltransferase) and HIOMT (hydroxyindole O-methyltransferase), as well as the melatonin receptors MT1 and MT2 in mouse primary chondrocytes and cartilage. Production of melatonin was confirmed by mass spectrometric analysis of primary rat and chick chondrocytes. Addition of melatonin to primary BALB/c mouse chondrocytes caused enhanced cell growth and increased expression of Col2a1, Aggrecan and Sox9, but inhibited Col10a1 expression. Addition of luzindole, an MT1 and MT2 antagonist, abolished these effects. These data indicate that chondrocytes produce melatonin, which regulates cartilage growth and maturation via the MT1 and MT2 receptors. Kinetic analysis showed that melatonin caused rapid upregulation of Aanat, Mt1, Mt2 and Pthrp expression, followed by Sox9 and Ihh. Furthermore, expression of the clock gene Bmal1 was induced, while that of Per1 was downregulated. Chronobiological analysis of synchronized $\mathrm{C} 3 \mathrm{H}$ mouse chondrocytes revealed that melatonin induced the cyclic expression of Aanat and modified the cyclic rhythm of Bmal1, Mt1 and Mt2. In contrast, Mt1 and Mt2 showed different rhythms from Bmal1 and Aanat, indicating the existence of different regulatory genes. Our results indicate that exogenous and endogenous melatonin work in synergy in chondrocytes to adjust rhythmic expression to the central suprachiasmatic nucleus clock.
\end{abstract}

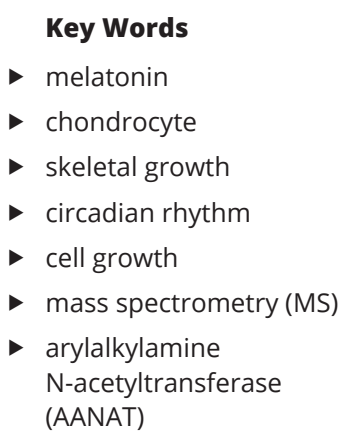

Journal of Endocrinology (2019) 241, 161-173

\section{Introduction}

The rate of fetal and juvenile skeletal growth is controlled, to a large extent, by the development and expansion of cartilaginous growth plates in the long bones, ribs and vertebrae. Parameters controlling the rate of chondrocyte proliferation, matrix deposition and differentiation events vary along a spatial gradient. These begin with high rates of cell division and hyaline cartilage matrix deposition in the proliferating zone and end after several steps of chondrocyte differentiation to form hypertrophic cells in the hypertrophic zone. 
The complex regulation of chondrocyte proliferation and hypertrophy during endochondral ossification involves numerous antagonistically and synergistically acting hormones, growth factors and their receptors and developmental control genes (Reddi 1994, Goldring et al. 2006, Shao et al. 2006, Liu et al. 2017).

There is considerable evidence to suggest that cartilage and bone growth in vertebrates oscillate in a circadian rhythm, but the exact mechanisms underpinning the circadian regulation of cartilage growth remain largely unknown. Russell et al. (1984) showed that the mineralization of rat growth plate cartilage occurs at night. Chondrocyte proliferation, however, occurs mostly in the early morning. The proliferative phase is followed by the expansion of the growth plate, which peaks at noon in rats (Stevenson et al. 1990), coinciding with the highest rate of collagen matrix synthesis (Igarashi et al. 2013).

The central mammalian circadian clock is located in the suprachiasmatic nucleus (SCN) of the hypothalamus and synchronizes the light/darkness cycles of peripheral organs via hormonal and neuronal mechanisms. Cycle periods are regulated by a transcriptional/translational feedback loop consisting of the transcriptional activators BMAL1/CLOCK and a repressor complex formed by PER1/PER2 and CRY1/CRY2 (Dudek \& Meng 2014). However, peripheral tissues are also capable of selfsustained circadian oscillation for $>20$ cycles when isolated from the central control, indicating the existence of organspecific synchronizers of circadian rhythm at the cellular and tissue levels (Yoo et al. 2004). A long-term mouse ex vivo organ culture study revealed a tissue-autonomous circadian rhythm that persisted for several months in both articular and growth plate cartilage (Okubo et al. 2013). Recently, several studies have demonstrated the rhythmic expression of clock genes in cartilage, indicating that, similar to the central SCN, the circadian clock in cartilage is regulated by a BMAL1/CLOCK-PER/CRY feedback loop (Takarada et al. 2012, Gossan et al. 2013, Okubo et al. 2013, Dudek et al. 2016).

The circadian clock of murine chondrocytes also regulates a number of catabolic and anabolic genes that control key aspects of cartilage homeostasis. For example, BMAL1 stimulates Indian hedgehog (Ihh) expression (Takarada et al. 2012). Accordingly, in the growth plates of BMAL1-null mice, expression of $I h h$ is decreased and the rhythmic expression patterns of both Per 1 and Ihh are disrupted (Takarada et al. 2012).

In cartilage, the cyclic expression of Bmal1 and Per1 can be modulated by PTH (1-34), the active peptide of parathyroid hormone (PTH) (Okubo et al. 2015, Kunimoto et al. 2016). Both PTH and the related cartilage-derived parathyroid-related peptide (PTHrP) signal through the PTH receptor PPR1 and are key factors in the control of chondrocyte differentiation (Chung et al. 1998). It has been shown that PTH (1-34) induces Per1 expression in osteoblasts and chondrocytes (Hinoi et al. 2006, Hanyu et al. 2011), thereby inducing phase shifts in the circadian rhythm during femoral growth (Okubo et al. 2015) and bone fracture healing (Kunimoto et al. 2016).

While PTH (1-34) is a humoral factor that controls the circadian clock in cartilage; melatonin, an indole primarily synthesized in the pineal gland during darkness, is a primary factor in the regulation of circadian rhythm throughout the entire body. In addition to the pineal gland, many other tissues and organs produce melatonin (Acuna-Castroviejo et al. 2014). Melatonin has also been reported to affect the chondrogenesis of mesenchymal stem cells (Gao et al. 2014) and stimulate cartilage matrix synthesis (Pei et al. 2009). Therefore, we hypothesized that melatonin might be an integral part of the autonomous circadian cycle in cartilage. Articular cartilage and a large portion of embryonic cartilage are not vascularized, meaning that chondrocytes are shielded from humoral influences. This raises questions about whether chondrocytes are able to respond to circulating melatonin or, alternatively, able to synthesize melatonin themselves as part of the cyclic feedback of chondrocyte metabolism.

We show, for the first time, that chondrocytes from several species express the melatonin-synthesizing enzymes arylalkylamine $\mathrm{N}$-acetyltransferase (Aanat) and $\mathrm{N}$-acetylserotonin O-methyltransferase (Hiomt), as well as the melatonin receptors Mt1 and Mt2 in peripheral regions of cartilage and hypertrophic cartilage in the growth plate, which are in close proximity to wellvascularized tissues. Furthermore, we demonstrate that melatonin can stimulate chondrocyte growth and regulate the expression of cartilage-associated genes including Ihh, type 2 collagen (Col2a1), Aggrecan (Acan), SRY (sex determining region Y)-box 9 (Sox9), and type 10 collagen (Col10a1). Expression of melatonin in rat and chick chondrocytes was further confirmed by mass spectrometry (MS) analysis. We show that melatonin modifies the rhythmic expression of Bmal1, Mt1 and Mt2 and enhances the rhythmic expression of Aanat mRNA in primary chondrocytes, supporting the involvement of melatonin in the regulation of cartilage growth and homeostasis. 


\section{Materials and methods}

\section{Primary cell cultures}

Chondrocytes were isolated from the ribcages of either embryonic day 18.5 (E18.5) or E19.5 BALB/C and C3H mouse embryos, as previously described (Hattori et al. 2010, Tomita et al. 2013). Primary chick (Gallus gallus) chondrocytes were isolated from the knee cartilage of E17.5 chick embryos. Primary rat chondrocytes were isolated from the ribcage cartilage of E20 rat embryos (Sprague-Dawley). For all experiments, cells were grown in Dulbecco's modified Eagle medium (DMEM) containing 10\% fetal calf serum (FCS) in dishes covered with aluminum foil to avoid light contamination, and passage was performed in a darkened room with minimum light. To synchronize circadian rhythm, serum concentration in the medium was reduced to $1 \%$ for $24 \mathrm{~h}, 50 \%$ for $2 \mathrm{~h}$, and then increased back to $10 \%$ for the duration of culture, as indicated in individual experiments. All animal experiments were conducted in accordance with the institutional rules following approval from the Animal Care and Use Committee of Okayama University in Japan (OKU-2018544).

\section{Isolation of total RNA}

Tissues from one or two mice at postnatal day 0 (P0) or chicks at E17.5 were harvested and homogenized using
Isogen reagent (Nippon Gene, Tokyo, Japan). Total RNA was collected and further purified using an RNeasy kit (Qiagen).

\section{Real-time polymerase chain reaction}

Resting/growing and hypertrophic cartilage samples from the ribcages of postnatal day 0 (P0) mice were prepared as described earlier (Hattori et al. 2010, Tomita et al. 2013). Chondrocytes were cultured in DMEM: nutrient mixture F-12 (DMEM/F-12) containing 10\% FCS for various lengths of time as indicated under dark conditions before the total RNA was harvested using an RNeasy kit. Primers used are listed in Table 1. Expression of Gapdh was used to standardize total amounts of cDNA; however, as Gapdh expression varied among samples, plasmids in which the amplified cDNA fragments had been cloned were used to generate standard curves for calculation of gene copy numbers/ $\mu$ g RNA.

\section{In situ hybridization}

In situ hybridization was performed on paraffin-embedded sections as previously described (Schmidl et al. 2006, Hattori et al. 2010), using digoxigenin-labeled mouse antisense RNA probes with anti-digoxigenin-labeled alkaline phosphatase and BM purple as a detection system. The probe for mouse Col2a1 was kindly supplied

Table 1 Primers used for real-time PCR analysis.

\begin{tabular}{|c|c|c|}
\hline \multirow[b]{2}{*}{ Genes } & Mouse $\left(5^{\prime}-3^{\prime}\right)$ & Chick $\left(5^{\prime}-3^{\prime}\right)$ \\
\hline & Mouse $\left(3^{\prime}-5^{\prime}\right)$ & Chick $\left(3^{\prime}-5^{\prime}\right)$ \\
\hline \multirow[t]{2}{*}{ Mt1 } & TCCTGTCTGTGTACCGCAAC & AGCCACCATCCTCATCTTCAC \\
\hline & CGAGGTCTGCCACAGCTAAA & TATATTTCCCGCGTTCCGCA \\
\hline \multirow[t]{2}{*}{ Mt2 } & GAAGGGCTCTTTGTCACCAGTTAC & GCAAGCTCAGGAACTCAGGTAA \\
\hline & GGTTCAGGAGCCCATAAACAAT & GCATTTCACCCAAAGTCCATCC \\
\hline \multirow[t]{2}{*}{ Aanat for BALB/c } & AGGGTTAGGAAGTGCCGGAT & TAGCAGGAAACACCCAGCCT \\
\hline & AGTGCGTTTGAGATTGAGCG & TCCCTAACAGATCCCCTGGA \\
\hline \multirow[t]{2}{*}{ Aanat for $\mathrm{C} 3 \mathrm{H}$} & CAAGTGCAGAGCAAGCAACC & \\
\hline & CTCAAACCAGCCCAGTGACA & \\
\hline \multirow[t]{2}{*}{ Hiomt } & GCCATCTACAGGTCGGAGG & GAGTGCTGCTGGTTGAATCG \\
\hline & GAAGGGCGAGAGGTCGAAG & CTGCTGTTCGCTCCTTTCCT \\
\hline \multirow[t]{2}{*}{ Sox9 } & ATCTGAAGAAGGAGAGCGAG & CGTTCTTCACCGACTTCCTC \\
\hline & TCAGAAGTCTCCAGAGCTTG & AGGAAGCTGGCTGACCAGTA \\
\hline \multirow[t]{2}{*}{ Acan } & GAGGAGAGAACTGGAGAAG & \\
\hline & GGCGATAGTGGAATACAA & \\
\hline \multirow[t]{2}{*}{ Ihh } & CTGGCTGCGATTCTTCACAC & \\
\hline & ACTGAGGTGCAAGCCCATCT & \\
\hline \multirow[t]{2}{*}{ Col10a1 } & TGCTGCCTCAAATACCCTTTCT & \\
\hline & TGGCGTATGGGATGAAGTATTG & \\
\hline \multirow[t]{2}{*}{ Vegf } & CCTGGTAATGGCCCCTCCTC & \\
\hline & CCCCATTGCTCTGTGCCTTG & \\
\hline \multirow[t]{2}{*}{ Mmp13 } & TCCTCGGAGACTGGTAATGG & \\
\hline & TGATGAAACCTGGACAAGCA & \\
\hline \multirow[t]{2}{*}{ Gapdh } & CAATGACCCCTTCATTGACC & ACTTTGGCATTGTGGAGGGT \\
\hline & GACAAGCTTCCCGTTCTCAG & ACGCTGGGATGATGTTCTGG \\
\hline
\end{tabular}


by Dr K von der Mark (University of Erlangen, Erlangen, Germany) (Schmidl et al. 2006, Hattori et al. 2010). Probes specific for mouse Mt1, Mt2 and Aanat were generated by PCR amplification and cloned into a pGEM-T Easy vector (Promega). Primers used for PCR amplification were as follows: Mt1, 5'-agtacgatccceggatctactcctgtacct-3' and 5'-acatcttggctgtgcacaacgagacaataa-3'; Mt2, 5'-taatttgtttgt ggtgagtctggccttggc- $3^{\prime}$ and $5^{\prime}$-ttggccttccttcgggcctggagcacca gt-3'; Aanat, 5'-tgttgaacatcaactccetgaaacctgagg-3' and 5'-ca gcceggcgcacggccggctgactgccc- $3^{\prime}$.

\section{Western blots}

Cultured cells were washed with PBS and harvested with $10 \mathrm{mM}$ Tris- $\mathrm{HCl}(\mathrm{pH} 8.0)$ in $150 \mathrm{mM} \mathrm{NaCl}, 1 \%$ Triton $\mathrm{X}-100$ and $0.1 \mathrm{mM}$ phenylmethylsulphonyl fluoride. We used $66 \mu \mathrm{g}$ of total protein for Western blot analysis. Primary antibodies against MT2 (LSBio, Seattle, WA, USA) and $\beta$-actin (Sigma) were used.

\section{Cell proliferation assay}

Mouse primary chondrocytes were seeded into 96-well plates at a density of $0.8 \times 10^{4}$ cells/well and incubated for $24 \mathrm{~h}$. The medium was changed, and then various concentrations of melatonin (N-acetyl-5-methoxytryptamine; Wako, Osaka, Japan) were added to wells. Cells were further incubated in the dark for 5 days, and cell density was measured with a 3-(4,5-dimethylthiazol-2-yl)-5-(3-carboxymethoxyphenyl)2-(4-sulfophenyl)-2H-tetrazolium (MTS)-based CellTiter 96 aqueous non-radioactive cell proliferation assay kit (Promega). To assess the inhibitory effects of luzindole (N-acetyl-2-benzyltryptamine, Wako) on melatonin signaling, cells were treated with $1 \times 10^{-4} \mathrm{M}$ luzindole for $1 \mathrm{~h}$, prior to melatonin exposure.

\section{Quantification of melatonin and related molecules}

Melatonin biosynthesis pathway products were monitored in primary chondrocytes harvested from E19.5 Sprague-Dawley rats by triple MS analysis. Conditioned media were collected after 3 days of culture, and cells were washed with PBS and harvested in $20 \mathrm{mM}$ Tris- $\mathrm{HCl}$ (pH 8.0) in $150 \mathrm{mM} \mathrm{NaCl}, 1 \%$ Triton $\mathrm{X}-100,0.1 \%$ sodium deoxycholate and $0.1 \mathrm{mM}$ phenylmethylsulphonyl fluoride. After centrifugation, small aliquots of cell lysates were used for determination of protein concentration. The remaining supernatants were precipitated with acetone and analyzed using an LCMS-8050 Triple Quadruple Liquid Chromatograph mass spectrometer coupled to an LC-30AD high-performance liquid chromatography (HPLC) system (Shimadzu, Kyoto, Japan) with an octadecylsilyl (ODS) column $(2.0 \mathrm{~mm} \times 150 \mathrm{~mm}, 3.0 \mu \mathrm{m}$ particle size; Tosoh Bioscience, King of Prussia, PA, USA).

For determination of AANAT activity, primary chondrocyte lysates from chick embryos were harvested in $10 \mathrm{mM}$ PBS (pH 6.5) and incubated with $1 \mathrm{mM}$ tryptamine$\mathrm{HCl}$ and $0.1 \mathrm{mM}$ acetyl-CoA at $37^{\circ} \mathrm{C}$ for $60 \mathrm{~min}$. The reaction was stopped with concentrated acetic acid, and the concentration of N-acetyltryptamine (NATP) produced was monitored as described for rat chondrocyte lysate.

Samples for analysis were loaded onto the HPLC column, which had been pre-equilibrated with $10 \mathrm{mM}$ ammonium acetate in $0.05 \%$ acetic acid at $25{ }^{\circ} \mathrm{C}$ and separated using a gradient of buffer A (10 mM ammonium acetate and $0.05 \%$ acetic acid in water) and buffer B (100\% methanol) starting at A95:B5 (vol:vol) and increasing to A50:B50. Melatonin, serotonin, N-acetylserotonin (in rat chondrocyte lysates) and NATP (in chick chondrocyte lysates) were quantified using MS with electro-spray ionization in multiple reaction monitoring mode. Transition values were confirmed by analysis of the four molecules as markers. Control of the instrument and data acquisition were carried out using LC solution software (Shimadzu). An external standard curve was run on the day of analysis. Assay sensitivity limits for melatonin, serotonin, N-acetylserotonin and NATP were as low as 11.1, 82.3, 61.2 and $274.1 \mathrm{fg}$, respectively, with a 2:1 signal-to-noise ratio. Intra- and inter-assay variation coefficients were 3.94 and $4.60 \%$ for melatonin, 3.60 and 9.05\% for serotonin, 3.98 and $6.14 \%$ for $\mathrm{N}$-acetylserotonin and 2.99 and $4.21 \%$ for NATP, respectively.

\section{Statistical analysis}

With the exception of circadian rhythmicity, all statistical analyses were performed using SPSS 22.0 software (IBM Japan). Data are expressed as mean \pm standard deviation (s.D.), with $P<0.05$ considered statistically significant. Circadian rhythmicity was analyzed using a program provided by Dr Ziyi Wang (https://github.com/wong-ziyi/ Cosinor_Analysis_of_Rhythms) that was modified from the Cosinor2 package of $R$ (https://cran.r-project.org/ web/packages/cosinor2/index.html) for the calculation of parameters (Bingham et al. 1982, Cornelissen 2014, Hessen et al. 2015). As we performed replicates for each experimental group, differences of $\tau$ between experimental groups were assessed using the Student's $t$-test. Statistical significance was accepted at $P<0.05$ and all analyses were performed using $R$ programming language with open source packages. 


\section{Results}

\section{Quantitative analysis of Mt1 and Mt2 expression in mouse tissues}

Real-time PCR analysis of RNA from several tissues of P0 BALB/c mice revealed that Mt1 mRNA expression levels were highest in brain and liver tissues, while $M t 2$ mRNA levels were highest in kidney and skin tissues. Cartilage was found to contain substantial levels of mRNA (copies/ug RNA) of both Mt1 (Fig. 1A, $1.77 \pm 0.32 \times 10^{4}$ ) and Mt2 (Fig. 1B, $1.53 \pm 0.20 \times 10^{4}$ ). For comparison, mRNA expression of the cartilage marker gene, Sox9, was highest in cartilage (Fig. 1C, $2.27 \pm 0.014 \times 10^{7}$ ).

\section{Localization of Mt1 and Mt2 mRNA in mouse cartilage}

Localization of melatonin receptor was examined in cartilage tissues of BALB/c mice in vivo. In situ hybridization analysis indicated relatively strong expression of $M t 1$ and Mt2 mRNA along the peripheral zone of cartilage and in the pre-hypertrophic and hypertrophic zones of the growth plate (Fig. 2A). To examine whether melatonin receptor expression levels exhibited a gradient from the vascularized cartilage-bone border and lower hypertrophic zone to the avascular zones of proliferating and resting cartilage, chondrocytes were separately collected from hypertrophic and non-hypertrophic ribcage cartilage. Analysis of gene expression revealed that Mt1 and Mt2 mRNA levels were higher in Col10a1, Vegf and Mmp13 mRNA-expressing hypertrophic chondrocytes compared with cells isolated from resting and proliferating cartilage (Fig. 2B). This could indicate that the response to melatonin is high in the vascularized cartilage-bone border. Resting/proliferating chondrocytes and hypertrophic chondrocytes were also found to contain MT2 protein, with relatively high levels detected in hypertrophic chondrocytes (Fig. 2C).

\section{Effects of melatonin on chondrocyte growth and gene expression}

To analyze the effects of melatonin on chondrocytes, primary chondrocyte cultures were prepared from the ribcage of E18.5 BALB/c mice. Melatonin was added to media at various concentrations, with or without luzindole (N-acetyl-2-benzyltryptamine, an antagonist of MT1 and MT2 receptors), and cells were cultured for 5 days. Analysis of cell density using an MTS-based assay revealed that melatonin at a final concentration of $1 \times 10^{-8} \mathrm{M}$ or $1 \times 10^{-6} \mathrm{M}$ stimulated cell growth by up to $20 \%$. Addition of luzindole at a 100 -fold molar excess $\left(1 \times 10^{-4} \mathrm{M}\right)$ compared with melatonin $\left(1 \times 10^{-6} \mathrm{M}\right)$ abolished the effect (Fig. 3A).
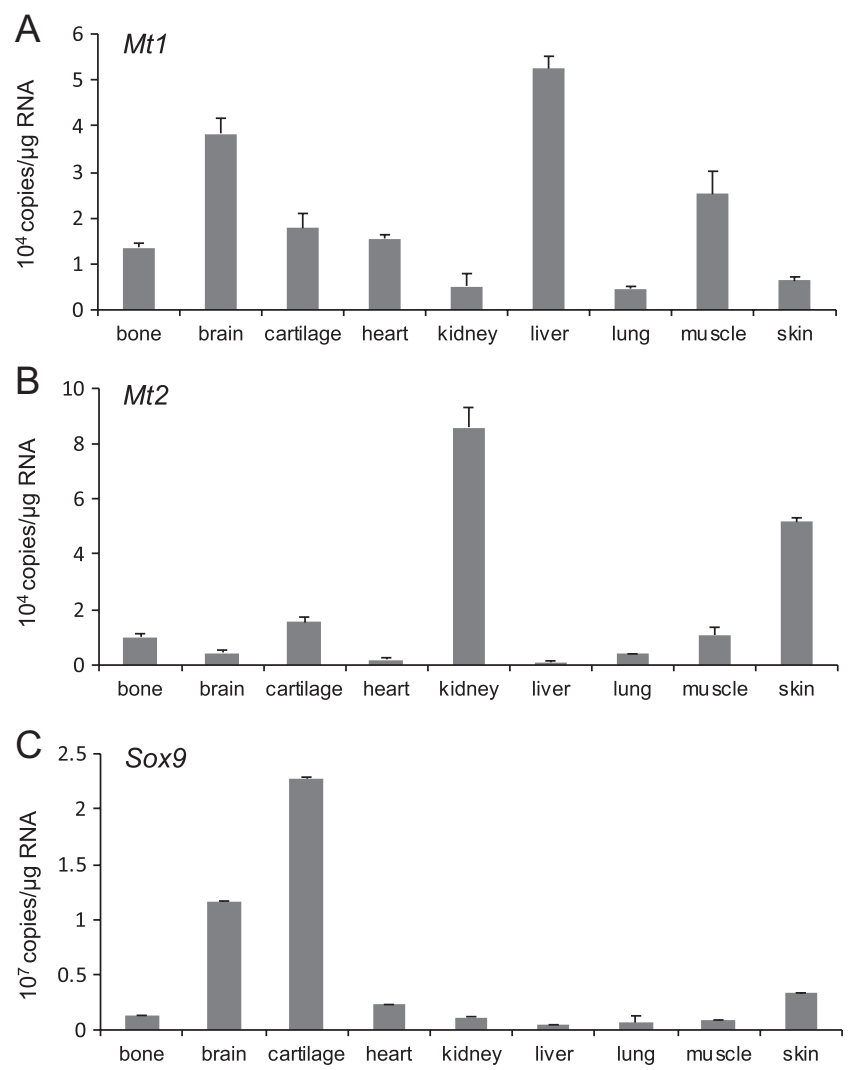

\section{Figure 1}

Expression of Mt1, Mt2 and Sox 9 mRNA in cartilage and other tissues of $\mathrm{BALB} / \mathrm{c}$ mice. Tissues from newborn (postnatal day 0, P0) BALB/c mice were harvested and total RNA was isolated. Expression of Mt1, Mt2 and Sox9 mRNA was detected in cartilage and other tissues, including brain. Data are shown as mean \pm S.D. $(n=3)$.

Luzindole $\left(1 \times 10^{-4} \mathrm{M}\right)$ itself was not cytotoxic, as indicated by the presence of lactate dehydrogenase in the conditioned medium (data not shown).

The effect of melatonin on the expression of chondrocyte differentiation markers was monitored. Mouse primary chondrocytes were cultured in various melatonin concentrations for 5 days before total RNA was purified and analyzed. Expression of Aggrecan and Ccn2, which encode enhancers of endochondral ossification, and Sox9, which encodes a strong inhibitor of chondrocyte hypertrophy, were upregulated by melatonin in a concentration-dependent manner (Fig. 3B, C and D). In contrast, expression of Col10a1 (which encodes a marker of chondrocyte hypertrophy) was downregulated and Ihh (which encodes a regulator of hypertrophic chondrocyte differentiation) was only weakly upregulated by melatonin (Fig. 3E and F). These results indicate that melatonin stimulates chondrocyte growth through MT1 and/or MT2 receptors, but inhibits chondrocyte maturation, possibly through induction of Sox9. 

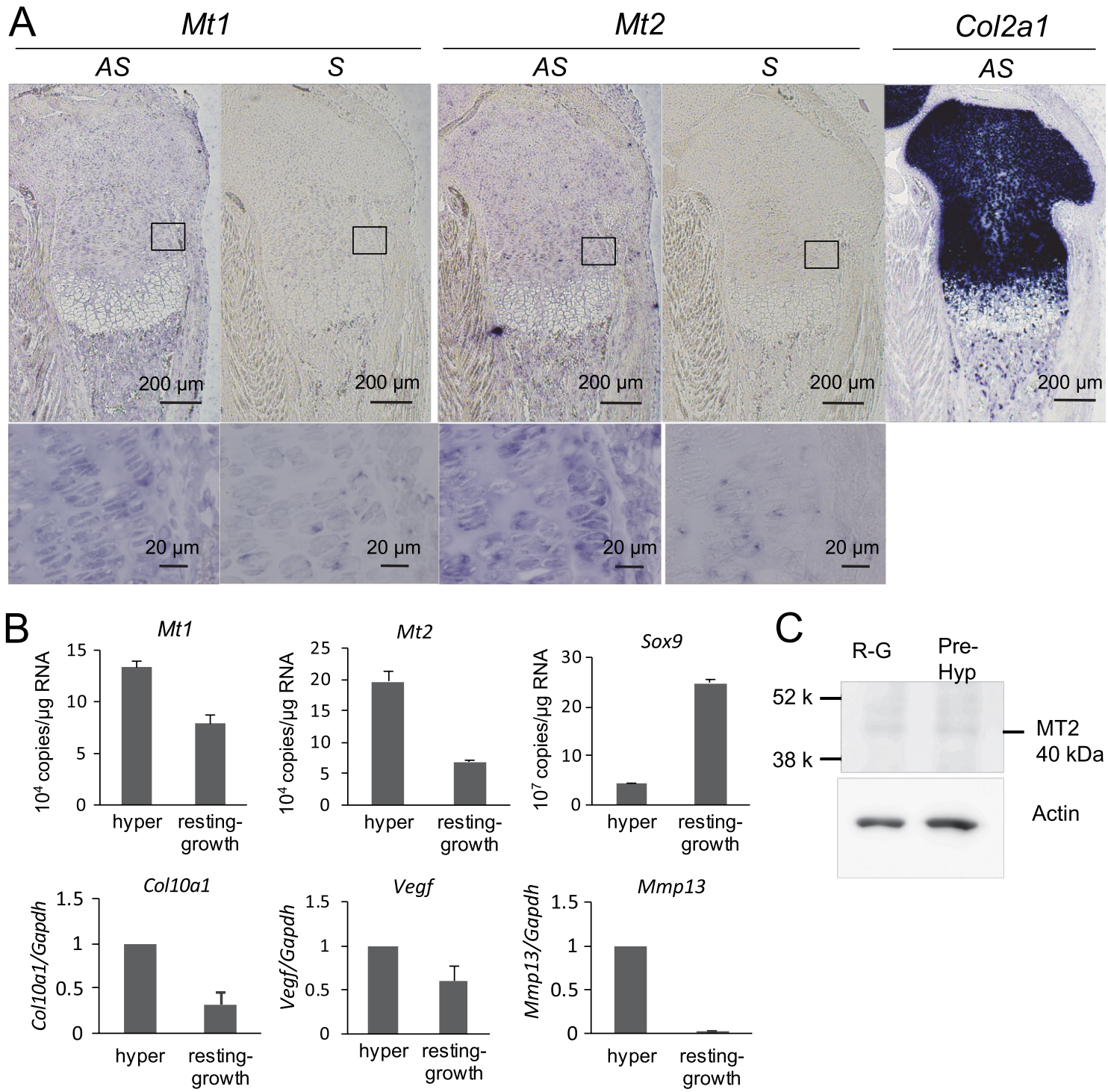

Figure 2

Detection of Mt1 and Mt2 mRNA and MT2 protein in cartilage. (A) In situ hybridization. Sections of tibiae from BALB/c mice at embryonic day 19.5 (E19.5) were fixed at 03:00 h. A Col2a1 probe was used as a marker of cartilaginous tissue. Key: AS, antisense probe; S, sense probe. Boxes in upper panels indicate the magnified regions shown in the lower panels. Scale bars: $200 \mu \mathrm{m}$ and $20 \mu \mathrm{m}$. (B) Comparison of gene expression in hypertrophic versus resting/proliferating chondrocytes. Hypertrophic cartilage and resting/proliferating cartilage were separately collected from BALB/c mouse ribcages at E18.5 and cultured. Hypertrophic chondrocytes were characterized by low expression of Sox9 mRNA and high expression of Col10a1, Vegf and Mmp13 mRNA. Expression levels of Mt1 and Mt2 mRNA were also higher in hypertrophic chondrocytes than in resting/proliferating chondrocytes. Data are shown as mean \pm s.D. $(n=3)$. $* P<0.05$, as determined by Student's $t$-tests. (C) Protein expression. Western blot analysis showed slightly enhanced MT2 protein levels in cultured hypertrophic chondrocytes compared with resting/proliferating chondrocytes. Actin was used as a loading control. A full colour version of this figure is available at https://doi.org/10.1530/JOE-19-0022.

\section{Detection of melatonin-synthesizing enzymes in cartilage}

Analysis of Aanat and acetylserotonin O-methyltransferase (Asmt) or Hiomt mRNA levels in the rib cartilage of newborn $\mathrm{BALB} / \mathrm{c}$ mice revealed high enough levels for detection (Fig. 4A; Aanat (copies/ $\mu$ g RNA): cartilage, $1.17 \pm 3.4 \times 10^{3}$; brain, $1.29 \pm 0.15 \times 10^{3}$; Hiomt: cartilage, $39.7 \pm 6.29$; brain: $69.9 \pm 25.9$ ). In situ hybridization indicated relatively strong expression of Aanat mRNA along the peripheral zone of cartilage, as well as in the pre-hypertrophic and hypertrophic zones of the growth plate (Fig. 4B).

\section{Melatonin production by chondrocytes}

Although expression of Aanat, Mt1 and Mt2 was detected at the level of transcription in chondrocytes from BALB/c mice, the levels of synthesis were too low to be detected at 

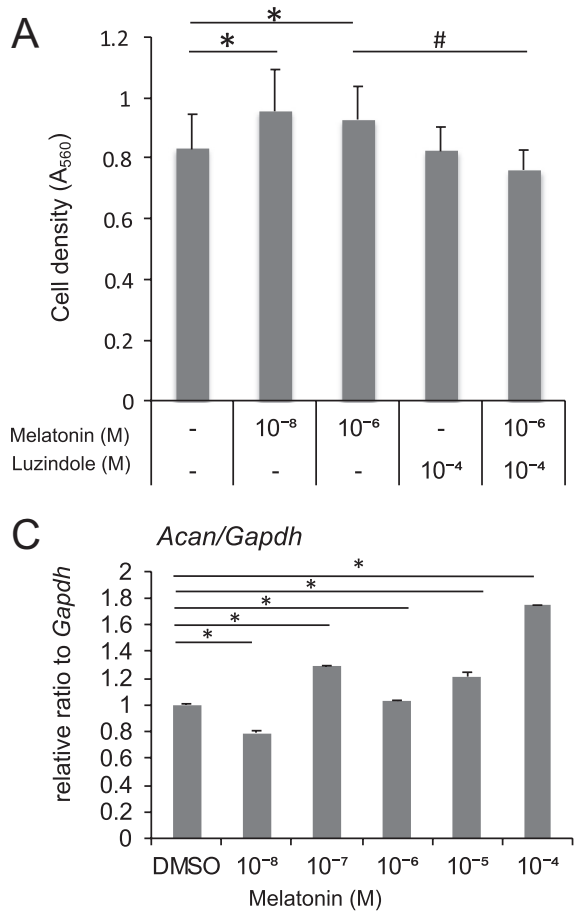

E

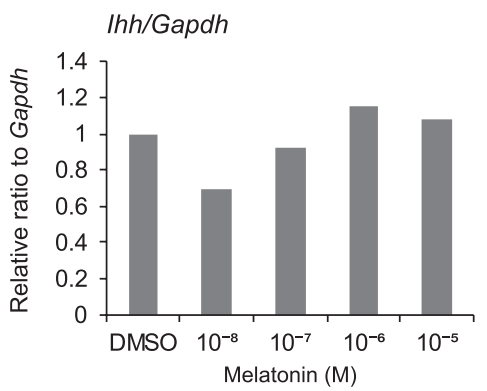

B
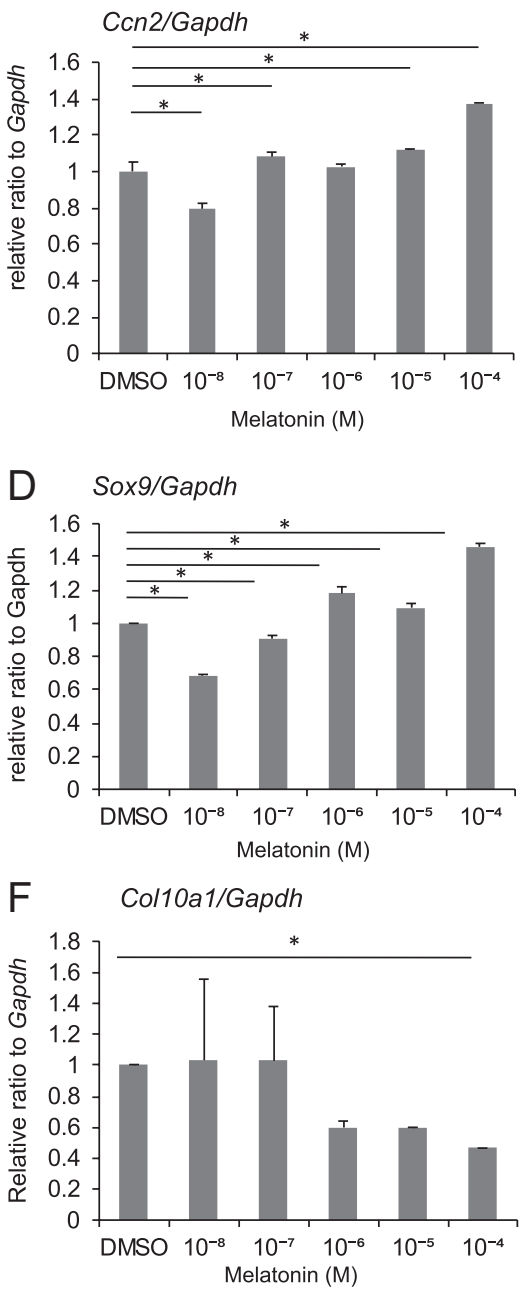

\section{Figure 3}

Melatonin stimulates chondrocyte proliferation and induces changes in gene expression. (A) Primary chondrocytes were isolated from the ribcages of BALB/c mice at embryonic day 18.5 (E18.5) and cultured for $23 \mathrm{~h}$. Luzindole or a vehicle control (dimethylsulfoxide) was added to the media, followed $1 \mathrm{~h}$ later by melatonin at the indicated concentrations. Afterward, cells were cultured for an additional 5 days in the dark. Cell density was measured with an MTS-based assay. Melatonin caused increased cell numbers with the greatest effect at $1 \times 10^{-8} \mathrm{M}$, while luzindole abolished melatonin-induced enhancement of cell proliferation. Data are shown as mean \pm S.D. $(n=12) .{ }^{*} P<0.05$ compared with melatonin $(-)$ /luzindole (-) group; \#\# $P<0.05$ compared with $10^{-6} \mathrm{M}$ melatonin, as determined by the Bonferroni test. (B-F) Mouse primary chondrocytes were plated, and $24 \mathrm{~h}$ later, melatonin was added at the indicated concentrations. Measurement of mRNA expression by real-time polymerase chain reaction revealed that $C \mathrm{Cn} 2$ (B), Acan (C), Sox9 (D) and $I h h(E)$ were upregulated by melatonin, while Col10a1 (F) mRNA levels decreased. Data are shown as mean \pm S.D. $(n=3)$. * $P<0.05$ compared with dimethylsulfoxide, as determined by one-way analysis of variance followed by Dunnett's post hoc test. the protein level, consistent with a report by Ebihara et al. (1986). Therefore, we analyzed melatonin production by rat chondrocytes using MS. Melatonin was detected in the conditioned medium collected after 3 days of culture $(0.94 \pm 0.66 \mathrm{pg} / \mathrm{mL})$, but not in fresh medium that had not been exposed to chondrocytes (control). Intermediates of melatonin synthesis from tryptophan, serotonin and N-acetylserotonin, were observed in the control media and in the conditioned media (data not shown). Melatonin was present in chondrocyte lysates $(37.79 \pm 25.74 \mathrm{pg} / \mathrm{mg}$ protein), but serotonin and $\mathrm{N}$-acetylserotonin were not detected.

\section{Detection of melatonin-synthesizing enzymes and receptors in chick chondrocytes}

In line with the results from mouse tissue, mRNA

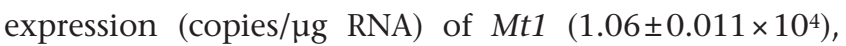

Mt2 $\left(2.2 \pm 0.14 \times 10^{4}\right)$, Aanat $\left(3.19 \pm 0.11 \times 10^{4}\right)$ and Hiomt $\left(7.27 \pm 0.62 \times 10^{4}\right)$ was observed in chick cartilage (Supplementary Fig. 1, see section on supplementary data given at the end of this article).

\section{Accumulation of melatonin and enhanced AANAT activity in chick chondrocytes}

Chick chondrocytes were cultured in the dark, and total RNA and cell lysates were collected and evaluated every $4 \mathrm{~h}$. The mRNA expression of Aanat peaked $18 \mathrm{~h}$ after the medium change (Supplementary Fig. 2A), which was followed by melatonin accumulation, peaking at $22 \mathrm{~h}$ after the medium change (Supplementary Fig. 2B). Using tryptamine as a substrate, cellular AANAT activity was monitored as NATP production by cell lysates. Maximum AANAT activity was observed $22 \mathrm{~h}$ after the medium change (Supplementary Fig. 2C). 
A
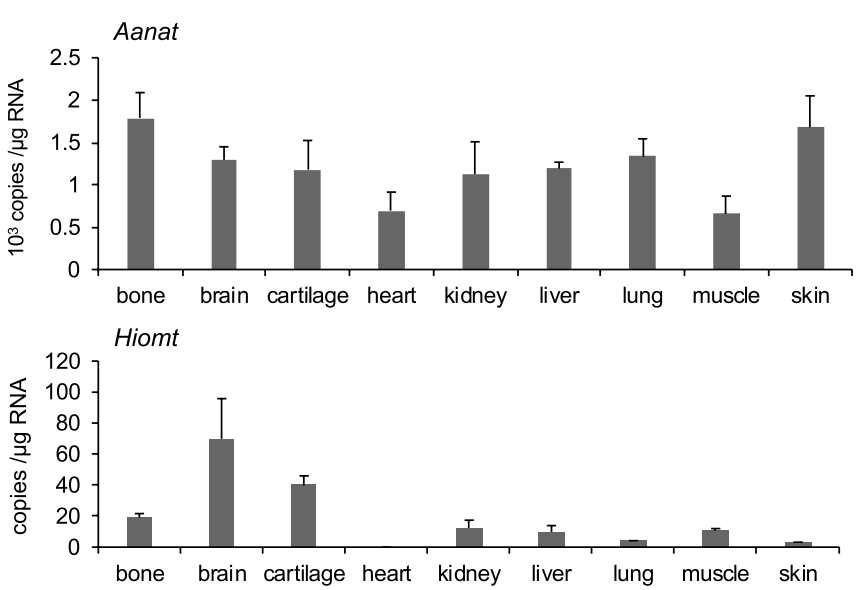

B Aanat

AS

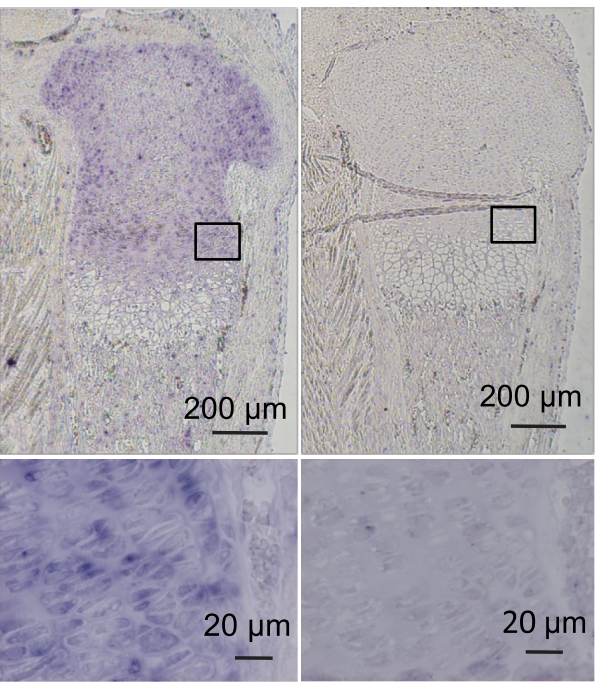

\section{Figure 4}

Detection of melatonin-synthesizing enzyme mRNA in cartilage and other tissues of BALB/c mice. (A) Tissues from newborn BALB/c mice were harvested and total RNA was isolated. Both Aanat and Hiomt mRNA were detected in cartilage and other tissues, including brain. Data are presented as mean \pm S.D. $(n=3)$. (B) In situ hybridization analysis of Aanat mRNA. Sections of tibiae from BALB/c mice at embryonic day 19.5 were fixed at 03:00 h, as performed for Fig. 2A. Key: AS, antisense probe; S, sense probe. Boxes in upper panels indicate magnified regions shown in lower panels. Scale bars: $200 \mu \mathrm{m}$ and $20 \mu \mathrm{m}$. A full colour version of this figure is available at https://doi.org/10.1530/JOE-19-0022.

These results demonstrate that cyclic expression of AANAT mRNA reflects cycles of enzymatic activity.

\section{Kinetic analysis of melatonin activity in chondrocytes}

Although chondrocytes are able to produce endogenous melatonin, they may still respond to circulating melatonin originating from the pineal gland. To investigate whether chondrocytes respond to melatonin in a timedependent manner, melatonin was added to cultured BALB/c chondrocytes, and total RNA was collected at regular intervals. Surprisingly, the addition of melatonin increased levels of Aanat, Mt1 and Mt2 mRNA after 30 min (Fig. 5A), indicating that chondrocytes exhibit a rapid response to melatonin stimulation and demonstrating the autoinduction of melatonin synthesis in these cells. Furthermore, melatonin-stimulated expression of Pthrp and $I h h$, which encode key factors in the regulation of chondrocyte differentiation in the growth plate, was observed. Melatonin was found to affect the expression of the transcription factor and clock gene, Bmal1, and inhibit Per1 expression (Fig. 5A). These results suggest that chondrocytes may themselves produce melatonin in response to circulating melatonin and also upregulate melatonin receptor expression, eventually synchronizing clock gene expression in chondrocytes with the central circadian clock.

The enhancement of Aanat and Ihh gene expression by melatonin in chondrocytes was abolished by exposure to luzindole (Fig. 5B).

\section{Melatonin modifies the circadian expression of Bmal1 and melatonin receptors in mouse primary chondrocytes and induces cyclic expression of Aanat}

As melatonin both enhanced mRNA expression of Aanat, Mt1 and Mt2 and altered Bmal1 and Per1 gene expression, we next examined the possibility that exogenous melatonin could affect also the cycle expression or period of BMAL1 (a master regulator), AANAT (a ratelimiting enzyme for melatonin synthesis) and melatonin receptor MT1 and MT2 genes. Primary BALB/c mouse chondrocytes were synchronized by culturing in DMEM containing $1 \%$ serum for $24 \mathrm{~h}$, followed by DMEM containing $50 \%$ serum for $2 \mathrm{~h}$. Subsequently, the media was changed to DMEM containing 10\% serum (normal condition, time point zero). Control chondrocytes were cultured continuously in DMEM containing $10 \%$ serum. Analysis of Bmal1 mRNA that was isolated from synchronized cultures every $4 \mathrm{~h}$ revealed cyclic 

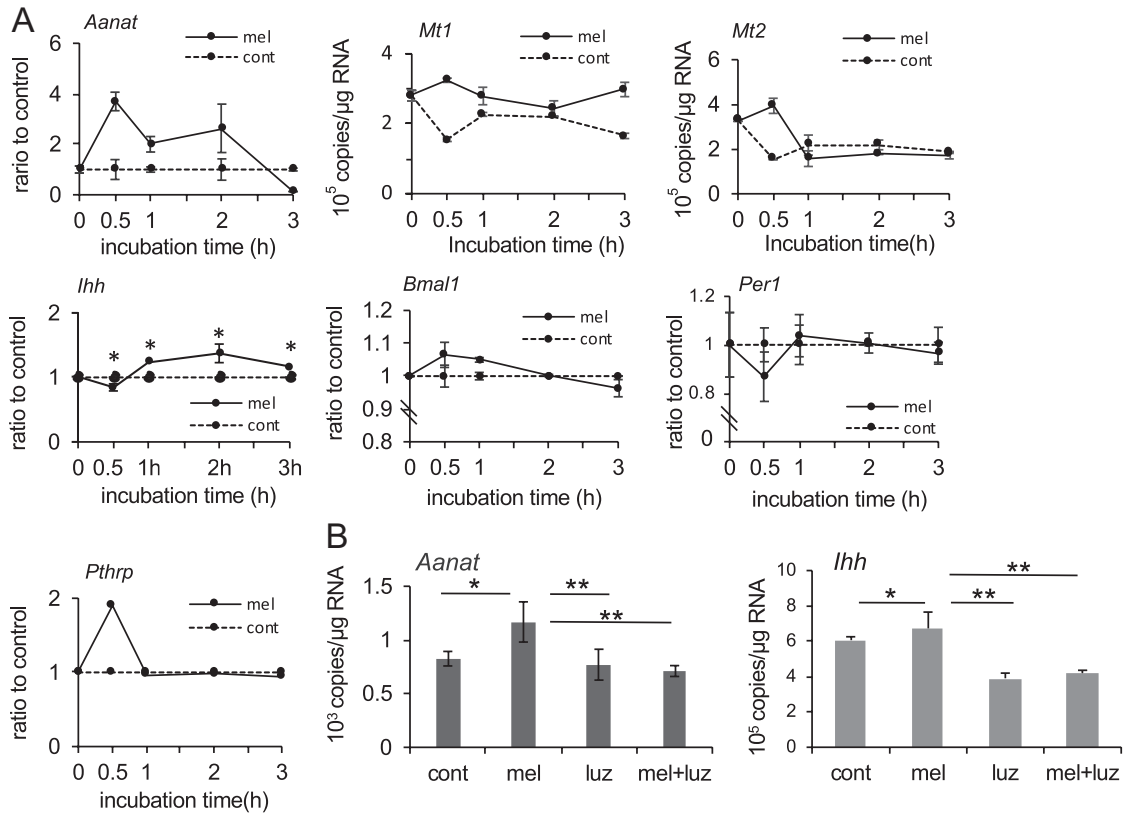

\section{Figure 5}

Effect of melatonin on gene expression in mouse primary chondrocytes. (A) Melatonin (at $1 \times 10^{-6} \mathrm{M}$ ) or dimethyl sulfoxide (control) was added to cells and total RNA was harvested at the indicated time points. Expression of Aanat, Mt1, Mt2, Bmal1 and Pthrp mRNA as significantly induced $0.5 \mathrm{~h}$ after the addition of melatonin, while $/ \mathrm{h} h$ mRNA expression was induced after $2 \mathrm{~h}$. Expression of Per 1 was inhibited at $0.5 \mathrm{~h}$. Data are presented as mean \pm S.D. $(n=3) .{ }^{\star} P<0.05$ compared with dimethyl sulfoxide, as determined by two-way analysis of variance and Tukey's post hoc test. (B) Inhibitory effects of luzindole, an MT1 and MT2 melatonin receptor antagonist, in mouse primary chondrocytes. Luzindole $\left(1 \times 10^{-4} \mathrm{M}\right)$ was added to cultures $1 \mathrm{~h}$ before the addition of melatonin. Total RNA was collected $2 \mathrm{~h}$ after melatonin addition. Upregulation of Aanat and $/ \mathrm{h} h$ mRNA by melatonin was abolished by luzindole. Data are presented as mean \pm S.D. $(n=3)$. ${ }^{*} P<0.05$ compared with control; $* * P<0.05$ compared with melatonin (+) group; as determined by one-way analysis of variance and Tukey's post hoc test. expression (22.63-h period, $P=9.7 \times 10^{-17}$; Fig. 6 A) with significantly higher amplitudes than was observed for unsynchronized cells. The addition of melatonin to synchronized BALB/c primary chondrocytes at different time points (9 and $13 \mathrm{~h}$ ) after synchronization moved the Bmal1 mRNA expression peak to $17 \mathrm{~h}$ after melatonin addition (Fig. 6B), indicating that exogenous melatonin modulates circadian expression of Bmal1 and other rhythmic gene expressions in BALB/c chondrocytes.

To confirm the cyclic expression of Bmal1, melatonin was added to BALB/c chodnrocytes $13 \mathrm{~h}$ after synchronization and RNA was collected every 4-h interval for over $58 \mathrm{~h}$. The addition of melatonin did not affect the rhythmic expression of Bmal1 (without melatonin: 23.28-h period, $P=0.04$; +melatonin: $22.68-\mathrm{h}$ period, $P=0.04$, significantly fitted to cosinor model, Fig. 6C). Rhythmic expression of Mt1 mRNA was observed only after the addition of exogenous melatonin (17.03-h period, $P=3.88 \times 10^{-9}$, Fig. $\left.6 \mathrm{D}\right)$. The Mt2 mRNA expression pattern was similar to that of $M t 1$; however, no significant rhythmic expression was observed $(P=0.07$, Fig. 6E). Analysis of Aanat mRNA in BALB/c chondrocytes did not show rhythmic expression either with or without the addition of melatonin (data not shown).

To analyze the effects of melatonin on chondrocytes which express higher levels of endogenous melatonin than BALB/c chondrocytes, C3H mouse primary chondrocytes were used and synchronized as described earlier. In $\mathrm{C} 3 \mathrm{H}$ mouse primary chondrocytes, exogenous melatonin induced the cyclic expression of Aanat mRNA with a 23.27-h period $(P=0.03$, Fig. 7A). Simultaneous analysis of Bmal1 mRNA revealed an 18.67-h cycle (Fig. 7B), while melatonin changed the Bmal1 expression rhythm from an 18.67-h period $(P=0.04)$ in control cells to a 23.34 -h period $\left(P=2.6 \times 10^{-5}\right)$, similar to the melatonin-stimulated expression rhythm of Aanat mRNA (Fig. 7B). Of note, the copy number of Bmal1 mRNA in $\mathrm{C} 3 \mathrm{H}$ chondrocytes was almost ten times lower $\left(0.3-1.0 \times 10^{5}\right.$ copies $/ \mu \mathrm{g}$ RNA $)$ than in BALB/c chondrocytes $\left(0.5-2.0 \times 10^{6}\right.$ copies/ $\mu g$ RNA). In contrast, Hiomt mRNA did not exhibit a cyclic expression pattern (data not shown). Interestingly, exogenous melatonin also caused an 8-h shift in the cyclic expression peaks of $M t 1$ and $M t 2$ mRNA in $\mathrm{C} 3 \mathrm{H}$ chondrocytes, without changing their circadian periods of $16.96 \mathrm{~h}$ (Mt1, +melatonin: $P=0.02$ ) and $16.93 \mathrm{~h}$ (Mt2, +melatonin: $P=0.007)$ or $17.42 \mathrm{~h}$ (Mt1, -melatonin: $P=0.08)$ and 17.14h (Mt2, -melatonin: $P=0.02$ ), respectively (Fig. 7C and $\mathrm{D})$. These results indicate that rhythmic expression of melatonin receptors is controlled by other regulators in addition to Bmal1.

\section{Discussion}

To the best of our knowledge, this is the first study to show that chondrocytes produce melatonin and express the melatonin-synthesizing enzyme AANAT and melatonin receptors MT1 and MT2. Melatonin production 
A

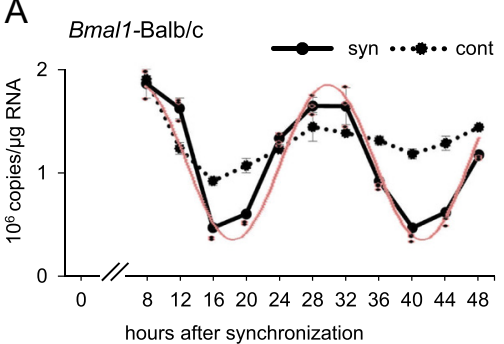

C

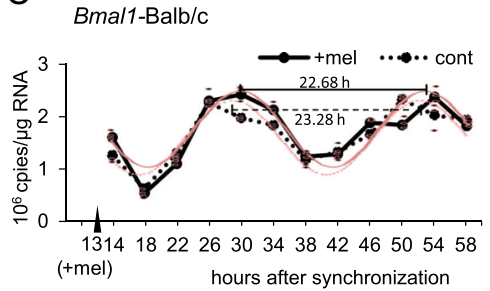

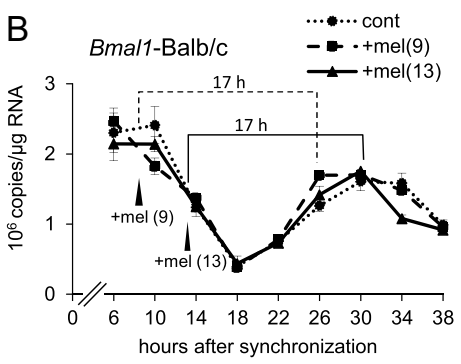

E
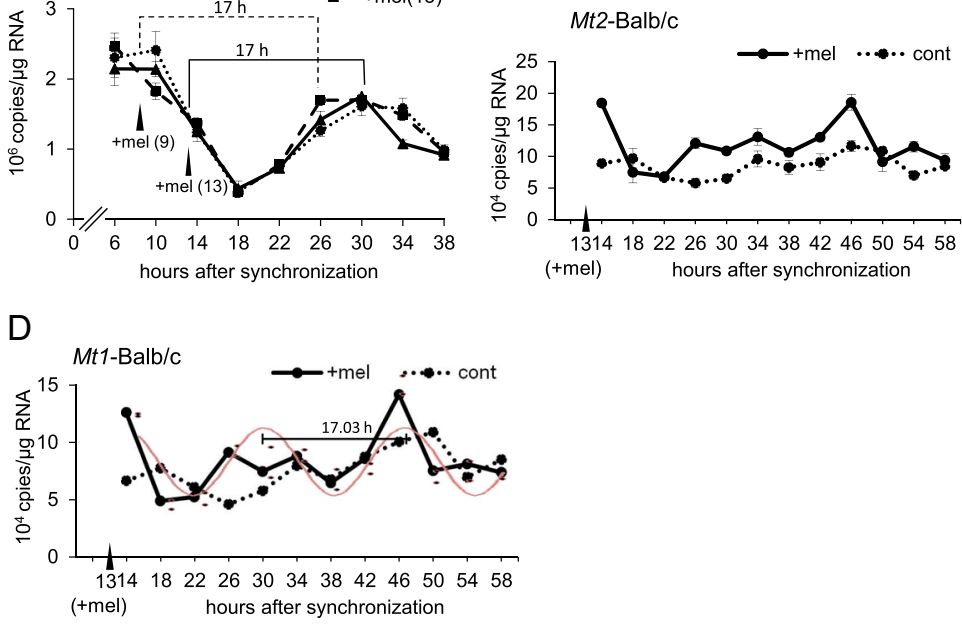

\section{Figure 6}

Cyclic expression and rhythm modification of Bmal1, Aanat and melatonin receptor mRNA by melatonin. (A) Primary chondrocytes isolated from BALB/C mice were plated on $3.5 \mathrm{~cm}$ dishes at a density of $4 \times 10^{5}$ cells/dish cultured for $48 \mathrm{~h}$ in the dark. For synchronization, half of the cells were placed in DMEM containing $1 \%$ serum for $24 \mathrm{~h}$ after reaching subconfluence, followed by $2 \mathrm{~h}$ in $50 \%$ serum. Subsequent passage into $10 \%$ serum-containing media was set as the $0 \mathrm{~h}$ timepoint. Solid line: synchronized cells. Dashed line: control cells (not synchronized, cultured continuously in $10 \%$ serum). Red line: fitting curve from the calculated formula. Total RNA was harvested every $4 \mathrm{~h}$. All experiments were performed more than four times and real-time polymerase chain reaction analysis using a cosinor 2 package in $R$, statistical significance was accepted at $P<0.05$. (A) After synchronization, the amplitude of the rhythmic expression of Bmal1 mRNA was strongly enhanced. (B) Addition of melatonin (at $1 \times 10^{-6} \mathrm{M}$ ) at various time points indicated by arrows to BALB/C chondrocytes synchronized and cultured as in (A) had no effect on the expression of Bmal1. Melatonin was added 9 or $13 \mathrm{~h}$, respectively, after synchronization (+mel(9) and +mel(13) indicated by arrows). Period time between melatonin additon and peak point is indicated. (C) BALB/c mouse primary chondrocytes were cultured and synchronized as described above. In the group (+mel), melatonin was added at final concentration of $10^{-6} \mathrm{M}$ after $13 \mathrm{~h}$ from synchronization as indicated by an arrow, and total RNA was collected at each indicated time point. Bmal1 expression did not show large changes in the circadian interval (23.47 h, -melatonin; $22.23 \mathrm{~h},+$ melatonin) or peak time point. (D) Mt1 mRNA showed circadian expression after the addition of melatonin with a $17.03 \mathrm{~h}$ circadian interval. (E) Although the expression pattern of Mt2 mRNA was similar to that of Mt1, no significant circadian expression was observed for either (+melatonin and -melatonin) groups. A full colour version of this figure is available at https://doi.org/10.1530/JOE-19-0022.

by chondrocytes was verified by mass spectrometric analysis of rat and chick chondrocyte lysates. We also demonstrate that mouse growth plate chondrocytes respond to melatonin via the MT1 and MT2 melatonin receptors. Melatonin-stimulated chondrocyte growth and expression of endochondral ossification markers such as CCN2, aggrecan, IHH a strong promoter of chondrogenesis (Tomita et al. 2013), and SOX-9 inhibitor of chondrocyte maturation (Hattori et al. 2010). However, expression of Col10a1, which encodes a marker of chondrocyte hypertrophy, was suppressed. This suggests that melatonin accelerates chondrocyte proliferation but inhibits terminal differentiation and hypertrophy.

Many mouse lines that have been established for research purposes do not produce melatonin in the pineal gland because they lack AANAT activity (Ebihara et al. 1986). Our experiments show that BALB/c mouse chondrocytes express the MT1 and MT2 receptors, as well as AANAT and HIOMT. These findings suggest that this mouse strain retains a melatonin signaling system. Although melatonin biosynthesis was below the detection level, it may have been decreased during strain establishment.

We also measured the synthesis of $\mathrm{N}$-acetyltryptamine by tryptamine, a serotonin analog, as an indicator of AANAT enzymatic activity in chick chondrocytes. The enzyme is particularly abundant in the pineal gland, which is the major site of melatonin synthesis (Stehle et al. 2011). This is consistent with the notion that melatonin may be produced in most cells that contain mitochondria, since melatonin is a mitochondria-targeted antioxidant (Reiter et al. 2016).

Surprisingly, kinetic analysis of the effects of melatonin on chondrocyte gene expression revealed rapid increases in Aanat, Mt1, Mt2 and Pthrp mRNA levels, indicating a rapid and enhanced response to melatonin. The increase in expression of $I h h$ mRNA in response to melatonin was delayed compared with other genes which were analyzed. This may indicate that the upregulation of Ihh by melatonin was modified through upregulation of Pthrp. Luzindole, an antagonist of melatonin receptors, abolished the enhancement of Aanat and Ihh 
A
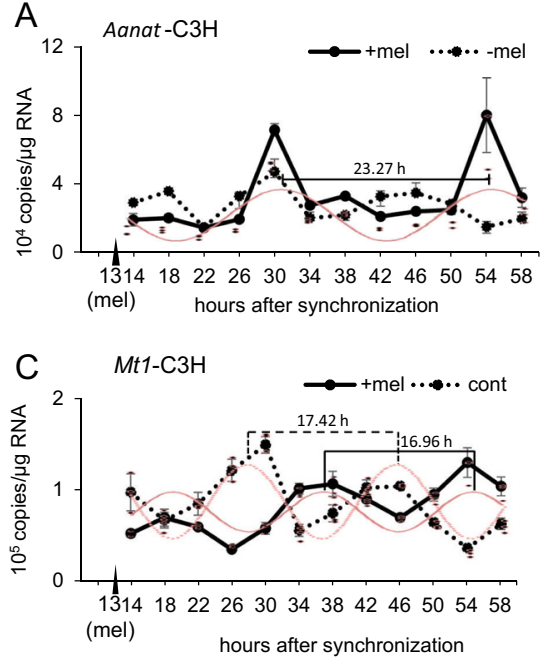
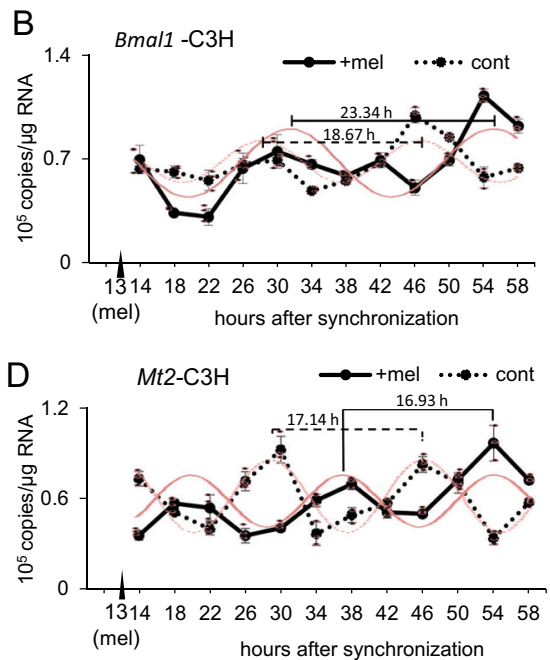

Figure 7

$\mathrm{C} 3 \mathrm{H}$ mouse primary chondrocytes were synchronized as described above and melatonin was added to a final concentration of $10^{-6} \mathrm{M} 13 \mathrm{~h}$ after synchronization (indicated by arrows), and total RNA was collected at each indicated time point. (A) In control cultures without melatonin, Aanat mRNA did not show a clear circadian rhythm; however, melatonin stimulation induced strong circadian expression $(P<0.05$; circadian interval was $23.27 \mathrm{~h}$ ). (B) In contrast to BALB/C chondrocytes, Bmal1 mRNA expression in $\mathrm{C} 3 \mathrm{H}$ chondrocytes responded to melatonin with a change the circadian interval from $18.67 \mathrm{~h}$ to $23.34 \mathrm{~h}$. (C and D) Expression of $M t 1$ and $M t 2$ mRNA showed similar circadian expression; intervals were $17.42 \mathrm{~h}$ (-melatonin) and $16.96 \mathrm{~h}$ (+melatonin) for Mt1, and17.14 h (-melatonin) and $16.93 \mathrm{~h}$ (+melatonin) for $M+2$. Red line: fitting curve from the calculated formula. All experiments were performed more than four times and real-time PCR analysis carried out with the cosinor2 package in $R$. Statistical significance was accepted at $P<0.05$. A full colour version of this figure is available at https://doi.org/10.1530/ JOE-19-0022.
mRNA production, confirming that the enhanced expression of these genes by melatonin is at least partially mediated by the MT1 and MT2 receptors. The addition of luzindole repressed $\mathrm{Ih} h$ expression, indicating an MT1/MT2 independent effect of luzindole.

Because relatively high levels of Aanat, Mt1 and Mt2 mRNA were observed in the peripheral regions and the hypertrophic zone of cartilage, avascular cartilage may respond differently to melatonin in an endocrine manner. Moreover, melatonin produced in cartilage may affect gene expression in a para/autocrine manner. Several in vitro studies have reported the effects of melatonin on chondrocyte metabolism (Pei et al. 2009, Gao et al. 2014), but it is difficult to compare results: for example, Gao et al. used relatively large melatonin concentrations to show that, at $5 \times 10^{-5} \mathrm{M}$, melatonin enhanced chondrogenic differentiation of human mesenchymal stem cells (Gao et al. 2014), while Pei et al. (Pei et al. 2009) showed that the mRNA and protein expression levels of type II collagen, SOX9 and aggrecan were enhanced by the addition of $4 \times 10^{-6} \mathrm{M}$ melatonin to porcine articular chondrocytes. Our results are largely consistent with these reports, confirming that melatonin enhances chondrocyte proliferation and the expression of cartilage-associated genes. However, a study using cultured chondrocytes from rat vertebral body growth plates showed that high concentrations of melatonin $\left(4 \times 10^{-4} \mathrm{M}\right)$ caused inhibition of cell proliferation and mRNA expression of Col2a1, Aggrecan, Sox9 and Smad4 (Zhong et al. 2013).
We used rib cartilage as a chondrocyte source, however, the effects of melatonin may vary among cartilage types (e.g. hyaline, fibrous and elastin cartilage) or, even among hyaline cartilages and permanent cartilages (e.g. articular or trachea cartilage). Also hypertrophic chondrocytes from growth plates may show different responses to melatonin. This needs to be further analyzed.

The concept of a tissue-autonomous circadian clock in cartilage has been described in previous studies, and the rhythmic expression of clock genes in articular and growth plate cartilage has been demonstrated: several studies have shown that the circadian clock in cartilage is regulated by a BMAL1/CLOCK and PER/CRY feedback loop (Takarada et al. 2012, Gossan et al. 2013, Okubo et al. 2013, Dudek et al. 2016). The key focus of our study was the effect of melatonin on the circadian cycle of cartilage growth. Our results demonstrate that exogenous melatonin upregulates Bmal1, but downregulates Per1, in chondrocytes, suggesting that melatonin modifies rhythmic gene expression. To analyze the effects of melatonin on rhythmic gene expression, primary BALB/c mouse chondrocytes were synchronized, and this synchronization enhanced the amplitude of Bmal1 mRNA expression, and the addition of melatonin changed the cyclic Bmal1 expression peaking $17 \mathrm{~h}$ after melatonin addition. Analyzing rhythmic gene expression using RNA collected every $4 \mathrm{~h}$ over $58 \mathrm{~h}$; however, the rhythmic expression of Bmal1 did not change following the addition of melatonin. Induction of the rhythmic expressions of 
Mt1 and Mt2 (not significant, but similar to Mt1 mRNA) was observed after addition of melatonin.

To investigate the effects of exogenous melatonin on melatonin synthesis and to investigate the endogenous melatonin effects in chondrocytes, we compared C3H mouse primary chondrocytes with BALB/c. In $\mathrm{C} 3 \mathrm{H}$ chondrocytes, exogenous melatonin enhanced the amplitude of Aanat mRNA expression and altered the rhythmic expression of Aanat and Bmal1 compared with the control group. This could be explained by the fact that melatonin modulates rhythmic gene expression by regulating Bmal1, a master regulator, and induces endogenous melatonin expression in cartilage. The cartilaginous melatonin could enhance rhythmic gene expression in a para/autocrine manner. Upregulated endogenous melatonin further regulates Bmal1 rhythmic expression in $\mathrm{C} 3 \mathrm{H}$ chondrocytes, and changes the Bmal1 rhythmic interval from $\sim 17$ to $\sim 24 \mathrm{~h}$. In contrast, $\mathrm{BALB} / \mathrm{c}$ chondrocytes without endogenous melatonin show a 24-h Bmal1 expression cycle which is not affected by melatonin addition, because Bmal1 levels in BALB/c cells is sufficiently high, whereas $\mathrm{C} 3 \mathrm{H}$ chondrocytes with a lower Bmal1 expression undergo an 18 -h Bmal1 expression cycle despite endogenous melatonin; only after the addition of exogenous melatonin, Bmal1 rhythmic expression cycle extends to $\sim 24 \mathrm{~h}$ as in Balb/c cells. This indicates that Bmal1 is the key factor in determining the circadian cycle in chondrocytes, but it is largely controlled by melatonin.

The Mt1 and Mt2 receptors showed different expression patterns in $\mathrm{BALB} / \mathrm{c}$ and $\mathrm{C} 3 \mathrm{H}$ cells. Our data indicate that $M t 1$ and Mt2 expression is induced in BALB/c chondrocytes only after melatonin stimulation. In synchronized cultures, addition of melatonin induced $M t 1$ and $M t 2$ rhythmic expression with a $\sim 17$-h period, because BALB/c chondrocytes retain the ability to respond to melatonin (via receptors, signal transduction and transcription control). In contrast to $\mathrm{BALB} / \mathrm{c}$ chondrocytes, $\mathrm{C} 3 \mathrm{H}$ chondrocytes showed rhythmic expression of Mt1 and Mt2 with a 17-h period in the absence of exogenous melatonin, due to higher levels of endogenous melatonin. The addition of melatonin to $\mathrm{C} 3 \mathrm{H}$ chondrocytes changed the cyclic expression peak by a 13-h shift, but the cycle period was unchanged, indicating that melatonin receptors may be regulated by rhythmic regulators other than BMAL1.

We were not able to detect the rhythmic expression of Aanat in BALB/c chondrocytes, although we did detect temporary induction of Aanat by melatonin. This may be due to the discontinuation of rhythmic induction of Aanat in BALB/c chondrocytes.

Kunimoto et al. (Kunimoto et al. 2016) have shown that PTH (1-34) is able to reset the cartilage circadian clock in murine femur organ culture, while a lack of BMAL1 caused disruption of the cyclic expression of $I h h$ and Per1 in cartilage (Takarada et al. 2012). Notably, our results show that melatonin stimulates Pthrp, Ihh and Bmal1 expression, but inhibits Per1 expression, suggesting that melatonin directly or indirectly regulates the expression of circadian clock-associated genes.

\section{Supplementary data}

This is linked to the online version of the paper at https://doi.org/10.1530/ JOE-19-0022.

\section{Declaration of interest}

The authors declare that there is no conflict of interest that could be perceived as prejudicing the impartiality of the research reported.

\section{Funding}

This work was supported by JSPS KAKENHI (grant number JP16K11476) and by funding from the Foundation for Growth Science, Ryobi Teien Foundation, by a SHISEIKAI Scholarship Fund for basic medical science researchers (Keiko Watanabe Award) and by China Scholarship Council to S Fu.

\section{Author contribution statement}

$\mathrm{TH}, \mathrm{MI}$ and $\mathrm{A} \mathrm{H}$ defined the research theme, designed the experimental approach and critically revised the manuscript. T H, S F, M K, S K, D H, Y S, $A T$ and $Y M$ designed the methods and experiments and carried out most experiments. T H, S F, T N, Y U, Y M, M I, A H and S K analyzed data and interpreted the results. $\mathrm{TH}$ wrote the manuscript.

\section{Acknowledgements}

The authors thank Dr Kenji Tomioka, Dr Takeshi Takarada and Dr Masaharu Takigawa for useful suggestions, and Yoshiko Miyake and Tomoko Yamamoto for technical and secretarial assistance. They also thank Dr Daisuke Ekuni, Dr Manabu Morita (Department of Preventive Dentistry) and Dr Ziyi Wang (Department of Orthodontics) for help with statistical analysis.

\section{References}

Acuna-Castroviejo D, Escames G, Venegas C, Diaz-Casado ME, LimaCabello E, Lopez LC, Rosales-Corral S, Tan DX \& Reiter RJ 2014 Extrapineal melatonin: sources, regulation, and potential functions. Cellular and Molecular Life Sciences 71 2997-3025. (https://doi. org/10.1007/s00018-014-1579-2)

Bingham C, Arbogast B, Guillaume GC, Lee JK \& Halberg F 1982 Inferential statistical methods for estimating and comparing cosinor parameters. Chronobiologia 9 397-439.

Chung UI, Lanske B, Lee K, Li E \& Kronenberg H 1998 The parathyroid hormone/parathyroid hormone-related peptide receptor coordinates (c) 2019 Society for Endocrinology Published by Bioscientifica Ltd. Printed in Great Britain 
endochondral bone development by directly controlling chondrocyte differentiation. PNAS 95 13030-13035. (https://doi.org/10.1073/ pnas.95.22.13030)

Cornelissen G 2014 Cosinor-based rhythmometry. Theoretical Biology \& Medical Modelling 11 16. (https://doi.org/10.1186/1742-4682-11-16)

Dudek M, Gossan N, Yang N, Im HJ, Ruckshanthi JP, Yoshitane H, Li X, Jin D, Wang P, Boudiffa M, et al. 2016 The chondrocyte clock gene Bmal1 controls cartilage homeostasis and integrity. Journal of Clinical Investigation 126 365-376. (https://doi.org/10.1172/JCI82755)

Dudek M \& Meng QJ 2014 Running on time: the role of circadian clocks in the musculoskeletal system. Biochemical Journal 463 1-8. (https:// doi.org/10.1042/BJ20140700)

Ebihara S, Marks T, Hudson DJ \& Menaker M 1986 Genetic control of melatonin synthesis in the pineal gland of the mouse. Science $\mathbf{2 3 1}$ 491-493. (https://doi.org/10.1126/science.3941912)

Gao W, Lin M, Liang A, Zhang L, Chen C, Liang G, Xu C, Peng Y, Chen C, Huang D, et al. 2014 Melatonin enhances chondrogenic differentiation of human mesenchymal stem cells. Journal of Pineal Research 56 62-70. (https://doi.org/10.1111/jpi.12098)

Goldring MB, Tsuchimochi K \& Ijiri K 2006 The control of chondrogenesis. Journal of Cellular Biochemistry 97 33-44. (https://doi. $\operatorname{org} / 10.1002 /$ jcb.20652)

Gossan N, Zeef L, Hensman J, Hughes A, Bateman JF, Rowley L, Little CB, Piggins HD, Rattray M, Boot-Handford RP, et al. 2013 The circadian clock in murine chondrocytes regulates genes controlling key aspects of cartilage homeostasis. Arthritis \& Rheumatism 65 2334-2345. (https://doi.org/10.1002/art.38035)

Hanyu R, Hayata T, Nagao M, Saita Y, Hemmi H, Notomi T, Nakamoto T, Schipani E, Knonenbery H, Kaneko K, et al. 2011 Per-1 is a specific clock gene regulated by parathyroid hormone (PTH) signaling in osteoblasts and is functional for the transcriptional events induced by PTH. Journal of Cellular Biochemistry 112 433-438. (https://doi. $\operatorname{org} / 10.1002 / j \mathrm{jcb} .22957)$

Hattori T, Muller C, Gebhard S, Bauer E, Pausch F, Schlund B, Bosl MR, Hess A, Surmann-Schmitt C, von der Mark H, et al. 2010 SOX9 is a major negative regulator of cartilage vascularization, bone marrow formation and endochondral ossification. Development 137 901-911. (https://doi.org/10.1242/dev.045203)

Hessen E, Nordlund A, Stalhammar J, Eckerstrom M, Bjerke M, Eckerstrom C, Gothlin M, Fladby T, Reinvang I \& Wallin A 2015 T-tau is associated with objective memory decline over two years in persons seeking help for subjective cognitive decline: A report from the Gothenburg-Oslo MCI Study. Journal of Alzheimer's Disease $\mathbf{4 7}$ 619-628. (https://doi.org/10.3233/JAD-150109)

Hinoi E, Ueshima T, Hojo H, Iemata M, Takarada T \& Yoneda Y 2006 Up-regulation of per mRNA expression by parathyroid hormone through a protein kinase A-CREB-dependent mechanism in chondrocytes. Journal of Biological Chemistry 281 23632-23642. (https://doi.org/10.1074/jbc.M512362200)

Igarashi K, Saeki S \& Shinoda H 2013 Diurnal rhythms in the incorporation and secretion of $3 \mathrm{H}$-proline and $3 \mathrm{H}$-galactose by cartilage cells and osteoblasts in various bone-forming sites in growing rats. Orthodontic Waves 72 11-15. (https://doi.org/10.1016/j.odw.2012.09.001)

Kunimoto T, Okubo N, Minami Y, Fujiwara H, Hosokawa T, Asada M, Oda R, Kubo T \& Yagita K 2016 A PTH-responsive circadian clock operates in ex vivo mouse femur fracture healing site. Scientific Reports 6 22409. (https://doi.org/10.1038/srep22409)

Liu CF, Samsa WE, Zhou G \& Lefebvre V 2017 Transcriptional control of chondrocyte specification and differentiation. Seminars in Cell \& Developmental Biology 62 34-49. (https://doi.org/10.1016/j. semcdb.2016.10.004)
Okubo N, Fujiwara H, Minami Y, Kunimoto T, Hosokawa T, Umemura Y, Inokawa $\mathrm{H}$, Asada M, Oda R, Kubo T, et al. 2015 Parathyroid hormone resets the cartilage circadian clock of the organ-cultured murine femur. Acta Orthopaedica 86 627-631. (https://doi.org/10.3109/17453 674.2015.1029393)

Okubo N, Minami Y, Fujiwara H, Umemura Y, Tsuchiya Y, Shirai T, Oda R, Inokawa H, Kubo T \& Yagita K 2013 Prolonged bioluminescence monitoring in mouse ex vivo bone culture revealed persistent circadian rhythms in articular cartilages and growth plates. PLOS ONE 8 e78306. (https://doi.org/10.1371/journal.pone.0078306)

Pei M, He F, Wei L \& Rawson A 2009 Melatonin enhances cartilage matrix synthesis by porcine articular chondrocytes. Journal of Pineal Research 46 181-187. (https://doi.org/10.1111/j.1600-079X.2008.00646.x)

Reddi AH 1994 Bone and cartilage differentiation. Current Opinion in Genetics \& Development 4 737-744. (https://doi.org/10.1016/0959437X(94)90141-O)

Reiter RJ, Mayo JC, Tan DX, Sainz RM, Alatorre-Jimenez M \& Qin L 2016 Melatonin as an antioxidant: under promises but over delivers. Journal of Pineal Research 61 253-278. (https://doi.org/10.1111/jpi.12360)

Russell JE, Grazman B \& Simmons DJ 1984 Mineralization in rat metaphyseal bone exhibits a circadian stage dependency. Proceedings of the Society for Experimental Biology and Medicine 176 342-345. (https://doi.org/10.3181/00379727-176-41880)

Schmidl M, Adam N, Surmann-Schmitt C, Hattori T, Stock M, Dietz U, de Crombrugghe B, Poschl E \& von der Mark K 2006 Twisted gastrulation modulates bone morphogenetic protein-induced collagen $\mathrm{II}$ and $\mathrm{X}$ expression in chondrocytes in vitro and in vivo. Journal of Biological Chemistry 281 31790-31800. (https://doi.org/10.1074/jbc. M603419200)

Shao YY, Wang L \& Ballock RT 2006 Thyroid hormone and the growth plate. Reviews in Endocrine \& Metabolic Disorders 7 265-271. (https:// doi.org/10.1007/s11154-006-9012-2)

Stehle JH, Saade A, Rawashdeh O, Ackermann K, Jilg A, Sebesteny T \& Maronde E 2011 A survey of molecular details in the human pineal gland in the light of phylogeny, structure, function and chronobiological diseases. Journal of Pineal Research 51 17-43. (https:// doi.org/10.1111/j.1600-079X.2011.00856.x)

Stevenson S, Hunziker EB, Herrmann W \& Schenk RK 1990 Is longitudinal bone growth influenced by diurnal variation in the mitotic activity of chondrocytes of the growth plate? Journal of Orthopaedic Research 8 132-135. (https://doi.org/10.1002/ jor.1100080117)

Takarada T, Kodama A, Hotta S, Mieda M, Shimba S, Hinoi E \& Yoneda Y 2012 Clock genes influence gene expression in growth plate and endochondral ossification in mice. Journal of Biological Chemistry $\mathbf{2 8 7}$ 36081-36095. (https://doi.org/10.1074/jbc.M112.408963)

Tomita N, Hattori T, Itoh S, Aoyama E, Yao M, Yamashiro T \& Takigawa M 2013 Cartilage-specific over-expression of CCN family member 2/ connective tissue growth factor (CCN2/CTGF) stimulates insulinlike growth factor expression and bone growth. PLOS ONE 8 e59226. (https://doi.org/10.1371/journal.pone.0059226)

Yoo SH, Yamazaki S, Lowrey PL, Shimomura K, Ko CH, Buhr ED, Siepka SM, Hong HK, Oh WJ, Yoo OJ, et al. 2004 PERIOD2::luciferase real-time reporting of circadian dynamics reveals persistent circadian oscillations in mouse peripheral tissues. PNAS 101 5339-5346. (https://doi.org/10.1073/pnas.0308709101)

Zhong ZM, Li T, Xu ZX, Meng TT, Zeng JH, Zheng S, Ye WB, Wu Q \& Chen JT 2013 Effect of melatonin on the proliferation and differentiation of chondrocytes from rat vertebral body growth plate in vitro. International Journal of Medical Sciences 10 1392-1398. (https://doi.org/10.7150/ijms.5645)

Received in final form 12 March 2019

Accepted 19 March 2019

Accepted Preprint published online 19 March 2019 https://joe.bioscientifica.com https://doi.org/10.1530/JOE-19-0022 (c) 2019 Society for Endocrinology Published by Bioscientifica Ltd. Printed in Great Britain 